\title{
Developing Value-Centric Business Models for Mobile Government
}

\author{
Chien-Chih $\mathrm{Yu}$ \\ Dept. of MIS, National ChengChi University, Taipei, Taiwan \\ ccyuanccu. edu. tw
}

\begin{abstract}
This paper proposes a value-centric business model (BM) framework and development process for building suitable business models to support the planning, implementation, operation, and evaluation of mobile government (MG) applications. MG stakeholders, values, systems, services, resources, costs, performances, as well as strategies and action plans are included as components to be specified in the BM framework. To achieve the objectives of creating value for all participating parties in the mobile government environment, four stakeholder and value perspectives taken into account are public beneficiaries, government internal organizations, government service chain, as well as society and nation. Based on the BM framework and value dimensions, a business model can be created by identifying and structurally linking values, objectives, systems, services, and performance measures for all stakeholders. To direct and facilitate the launching and evaluation of mobile government programs based on a value-centric business model, an adaptive balanced scorecard (BSC) with other methods and tools are used.
\end{abstract}

Keywords: Business model, value creation, mobile government, Balanced Scorecard, performance measurement.

\section{Introduction}

Mobile government (m-government, MG) can be collectively referred to as the adoption of mobile technologies to enhance e-government (EG) functionalities for enabling citizens, businesses, and agencies, with the use of mobile devices, to access government information and services, to exchange documents, knowledge, and experiences, as well as to participate and/or collaborate in government related activities $[26,27,30]$. Specific functional features of mobile networks and systems such as mobility, ubiquity, portability, accessibility, and localization provide new forms of connections, communications and interactions among stakeholders in the online government services environment. The aims are to eventually create added value and benefits for all MG participants. Value proposed and created for MG users and participating parties include convenience, efficiency, effectiveness, personalization, cost reduction, profitability, productivity, accountability, transparency, etc. [33]. Major identified MG service domains include m-communication (notice and mail), m-public services (transaction and payment), m-administration (internal operation and document 
management), m-democracy (voting and participation), and m-communities (user generated content sharing and social networking) [4,30]. Business model (BM), on the other hand, has been defined as an architecture of the information, product and financial flows, including a description of the various business actors and their roles, a description of the potential benefits for the various business actors, and a description of the sources of revenues [25]. Commonly mentioned BM types in the e-business domain include business-to-consumer (B2C), business-to-business (B2B), and consumer-to-consumer $(\mathrm{C} 2 \mathrm{C})$, etc. In the e-government literature, identified $\mathrm{BM}$ categories include government-to-citizens (G2C), government-to-businesses (G2B), government-to-government $(\mathrm{G} 2 \mathrm{G})$, government internal efficiency and effectiveness (IEE), and overarching infrastructure (Cross-cutting) [14]. Similarly, in the mgovernment applications, adopted BM types include m-government-to-citizen (mG2C), m-government-to-business $(\mathrm{mG} 2 \mathrm{~B})$, m-government-to-government $(\mathrm{mG} 2 \mathrm{G})$, and $\mathrm{m}$ government-to-employee (mG2E) [18].

It has been noted that value proposition and creation are central tasks for the development and delivery of electronic/mobile business and government services. In the mean time, business models have been pointed out as proper means to illustrate the concepts and methods for value proposition, creation, capture, and assessment in business and government domains [1,5,11,12,16,18,24,31,33,34]. Therefore, e-/mgovernment related business modeling should focus on specifying values and their relationships with other structural components to facilitate value creation for all stakeholders through EG/MG services system development and operation. Developing and conducting suitable mobile business models are thus critical to the success in promoting and delivering mobile public services, creating mobile public values for stakeholders, as well as sustaining continuous operation of MG services systems. In recent years, although emerging issues regarding value creation and business model development for m-government have attracted increasing attentions, an integrated BM framework and process for guiding the construction of a valuecentric MG business model are still lacking in the literature. This goal of this paper is to propose a value-centric business model framework and development process for building business models to support the planning, implementation, operation, and evaluation of mobile government systems and applications. The rest of this paper is organized as follows. In section 2, a brief literature review on value creation and business models is provided. In section 3, an integrated MG business model framework is presented based on value chain and value management concepts. In section 4, the development process of business model suitable for m-government based on design science is illustrated. Conclusion and future research directions are provided in the final section.

\section{Literature Review}

In both research and practices, previous works regarding value creation and business modeling for mobile government are still very limited. In this section, a brief literature review on value creation and business model for e-/m-business and 
e-/m-government is provided as a foundation for developing a value-centric business model framework suitable for mobile government applications.

\subsection{Value Creation in e-/m-Business and e-/m-Government}

In the e-commerce and e-business domain, value is defined as the amount buyers are willing to pay for what a firm provides them. It also refers to a preferred combination of benefits that services afford the end users compared with acquisition costs [2]. In the value chain and value management context, value proposition is a statement of what and how value is to be delivered to customers, or is referred to as an equation of the all positive factors that interest the individual and value chain partners. Value creation can be realized as the contribution of utilizing the final products and services to end users, as well as of attaining productivity and profit to the firm and other value chain participating parties. Value capture is defined as the difference between benefits/revenues and costs eventually retained by customers and the firm as well as other chain participants. Being considered as a cycle of value creation, communication, capture, and assessment stages, the value management process generally involves developing and structuring objectives for all stakeholders, establishing a value proposition, creating a value based measurement framework, developing briefs and specifications, designing and reviewing options, and assessing outputs and outcomes $[3,7,9,10,18]$. As for value model or framework in the ebusiness domains, Barber (2008) provides two frameworks based on the balanced scorecard (BSC) to incorporate both the tangible and intangible value aspects [3]. Keen and Williams (2013) propose a three dimensional value architecture to fit the dynamic nature of innovation and to sustain business growth [12]. For m-business specific value creation, Nah, Siau, and Sheng (2005) present a value-focused thinking procedure in which identify values, convert values to objectives, distinguish between means and fundamental objectives, and build means-ends objective network are listed as four consecutive steps [17]. Lariviere et al (2013), focusing on value in the mobile and social media environment, emphasize the concept of value fusion that aims at achieving value for the entire network of consumers and firms [13].

In the e-government domain, typical public and social values concerned in the public sector include equal opportunities, privacy, security, personalization, accountability, transparency, and participation, etc. Among previous works presenting value related framework, Hossain et al (2011) specify the measurement of EG system value in three dimensions including organizational efficiency, operational transparency, and public satisfaction [8]. Luna-Reyes, Gil-Garcia, and Romero (2012), aiming at creating value for government, citizens, and other end users, propose a three dimensional performance measurement model comprising EG determinants, EG characteristics, and EG results [16]. As for very few works addressing mobile government value models, Trimi and Sheng (2008) identify MG value-added advantages in various aspects including improving the delivery of government information and services, providing best solutions to Internet connectivity problems and digital divide issues, offering a more cost-effective choice for national networking, helping to avoid problems of corruption and low 
productivity, as well as increasing government employees' efficiency and effectiveness [27]. Yu (2013), considering value as tangible and intangible benefits perceived by and exchanged between stakeholders in the MG value chain, presents a three dimensional value framework encompassing functional features, user acceptance, and user benefits. The user benefits dimension is further classified into four specific constituent categories, namely, public beneficiaries, government officers and employees, participating parties of the government service chain, as well as society and nation [33].

It can be seen that since issues of value creation regarding mobile government applications are largely unexplored and no consensus in views and architectures of MG value exists, more research efforts in the direction of developing an integrated value framework for m-government are strongly demanded.

\subsection{Business Models in e-/m-Business and e-/m-Government}

Business model is widely used to depict the design of transaction content, structure, and governance for creating value through the exploitation of business opportunities [2]. To develop and implement an appropriate business model is a key to success and a crucial source of value creation for the firm, its customers, and all value chain participants. Commonly mentioned BM types include e-shop, e-marketplace, virtual communities, etc. when business functions are highlighted, or mobile portals, platform operators, wireless gateway and service providers, mobile application and content providers when mobile environment is involved.

As for component structures of e-business models proposed in the literature, Afuah and Tucci (2001) identifies value, scope, revenue sources, pricing, connected activities, implementation, capabilities, and sustainability as BM related elements [1]. $\mathrm{Yu}$ (2005) provides a business model framework with four value dimensions including market, supply chain, customers, and business organizations [31]. Osterwalder and Pigneur (2010) present an e-business model ontology that includes four component groups i.e. infrastructure, offering, customers, and finances [19]. As for the m-business domain, Schubert and Hampe (2006) adopt four main components including value proposition, product or service, value architecture, and revenue model to describe business models for mobile communities [29]. By adopting a design research perspective, de Reuver, Bouwman, and Haaker (2009) point out four domains (STOF), namely service, technology, organization and finance, for assigning common model components to build mobile business models [5]. To design mobile value co-creation services, Schmidt-Rauch and Schwabe (2014) adopt a user-centered design process (UCD) based on the design science methodology that emphasizes on a build-and-evaluate loop with five major steps [22].

As for BM component structures for e-government, only very limited efforts have been undertaken previously. Among these few works, Janssen and Kuk (2007) propose an EG-applicable BM framework that comprises six elements, namely, organizations in the public service network, service offerings, network coordination, business processes, shared resources, and network capabilities [11]. Towards developing a value-based e-government services framework, Yu (2008) proposes a 
BSC-based business model to highlight four value dimensions including public beneficiaries, government organizations and processes, government service chain, as well as society and national/global environments. Model elements specified in each of the four BM perspectives include values, stakeholders, services, systems, and performances [32]. Peinel, Jarke, and Rose (2010), in their work of presenting a business modeling approach for e-government services, identify value chain, partners, object exchange, role, services, policy, and advantage/disadvantage as BM elements [21]. Panagiotopoulos et al (2012), focusing on evaluating ICTs in public engagement, adopt a business model perspective that consists of four dimensions including value proposition (effects), value network (actors), value architecture (resources), and value finance (costs) [20]. For m-government specific business models, it is still a relatively unexplored area. Some researchers treat m-government as a subset of e-government and simply present mobile characteristics within the aspects of conventional G2C, G2B, and IEE business model types [18,27]. By illustrating an example of m-government services project, Peinel, Jarke, and Rose (2010) use the similar approach as in e-government cases to identify options of value chain with public and private partners, as well as their relationships with individual advantages and disadvantages [21]. For addressing the m-government adoption with the focus on public-private partnerships (PPP), ITU (2011) describes a basic MG business model that contains a set of constructs including user groups of mobile services, specific benefit and value to user groups, revenue or benefit to the providers/partners, processes and activities, resources and competencies, costs, and suppliers of required resources [9]. To address the design issues of service platform and business model for mobile participation (MP), de Reuver, Stein, and Hampe (2013) adopt the STOF business model framework to the public domain aiming for creating MP services value [6].

The design and implementation of m-government specific business models, although considered as crucial to the success of m-government, are still less touched issues in the literature. Previous works discussing MG related business model framework, development process, and performance evaluation are extremely scarce in both research and practices. Therefore, more research endeavors are needed to explore mobile business model issues in the m-government domain.

\section{Value-Centric Business Model Framework for M-government}

By integrating different views from previous works and taking a value chain perspective, value in mobile government refers to functional features and acceptance characteristics of MG systems and services, as well as tangible and intangible benefits perceived and captured by MG stakeholders. To facilitate value proposition, creation, and management, MG users and stakeholders are further classified into four constituent groups including public beneficiaries, government agencies, government service chain participants, as well as society and nation. A value-centric business model framework for mobile government (MGvBM) can then be formed to structurally organize stakeholders, values, systems, services, performances, and 
associated resources, costs, functions, processes, and activities for all stakeholder groups and value dimensions. Figure 1 depicts the value-centric business model framework with major model components and their relationships. Key MGvBM components with related elements and factors are described below.

MG stakeholders: MG stakeholders are actors involve in the m-government services environment. For the four classified constituent groups mentioned above, potential MG stakeholders include (1) citizens, businesses, communities, and NGOs for the public beneficiaries group, (2) local authorities, internal organizations, and employees for the government agencies group, (3) wireless and mobile network operators, mobile content and application service providers, mobile device and software/hardware vendors, mobile payment and financial service providers, mobile security and trust service providers, horizontal and/or vertical integration of participated government agencies for the group of government service chain participants, as well as (4) other actors in the society and national environments for the society and nation group.

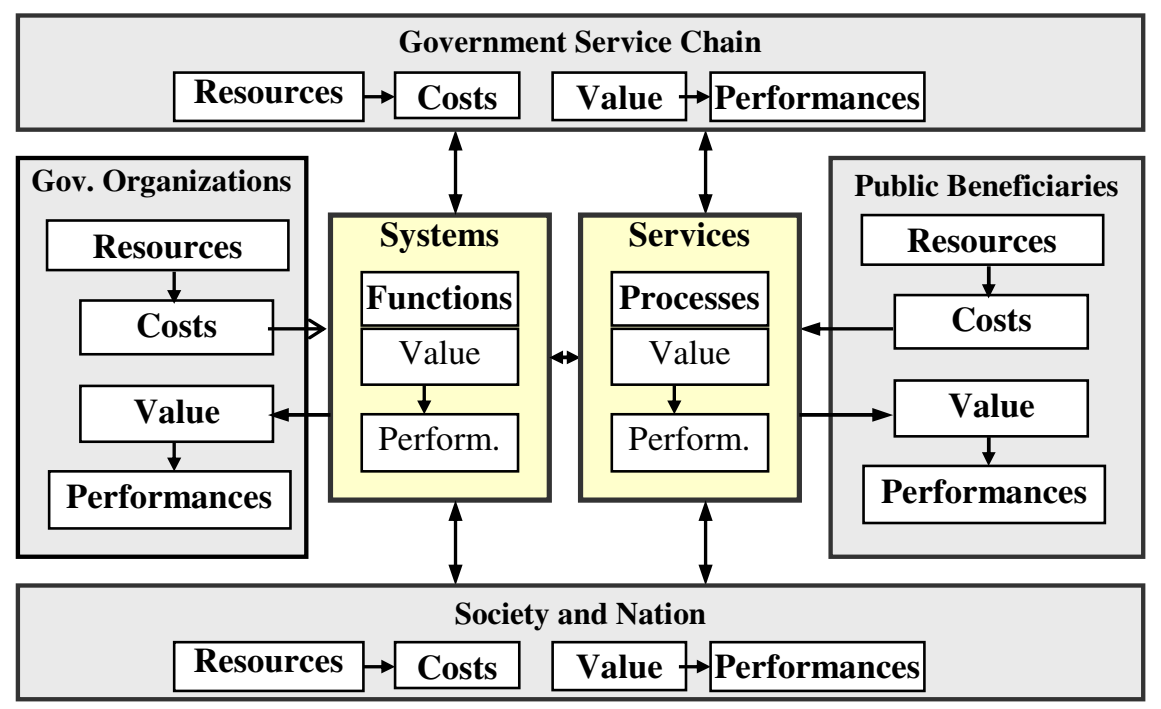

Fig. 1. A value-centric business model framework for mobile government

MG systems: MG systems involve mobile related networks, infrastructure, platforms, channels, devices and hardware/software that provide integrated functions for service providers to offer and maintain, as well as for users to access and utilize $\mathrm{MG}$ services in a secure and trust environment. $\mathrm{MG}$ system types include mG2C, mG2B, mG2E, mIEE, mG2G, etc, or m-gateway, m-cloud, m-tax, mtourism, etc. System functions may include profile management, search and navigation, transaction and payment, personalization and collaboration, tracking and monitoring, community and social networking, voting and participation, etc. Functional features include mobility, ubiquity, portability, accessibility, personalization, localization, multimedia data handling, and GPS-capability, etc. 
MG services: MG services are functional oriented and categorized value-added objects that are developed by government and associated service chain participating parties to enable users in accessing government information, exchanging personal experience and comments regarding government transactions, engaging with government agencies and/or service chain partners, and participating in government activities, etc. MG services are often classified as $\mathrm{mG} 2 \mathrm{C}, \mathrm{mG} 2 \mathrm{~B}, \mathrm{mG} 2 \mathrm{E}$, and $\mathrm{mG} 2 \mathrm{G}$ services, as $\mathrm{m}$-information, m-transaction, m-payment, m-community, m-administration, and m-democracy services, or as $\mathrm{m}$-tourism, m-taxation, m-healthcare, m-learning, m-agriculture, and m-police services, etc.

MG values: MG values refer to tangible and intangible benefits that are proposed to, created for, and captured by all MG stakeholders. Also identified as MG values include function, process and acceptance features of the MG systems and services. Specific MG values for stakeholder groups include citizen value, business value, and NGO value, employee value and organization value, service chain value, as well as society value and nation value. Value elements are specific functions and benefits corresponding to various value types in different services systems and stakeholder groups. For instance, value elements of systems and services value and public beneficiaries value in a m-tax services system include mobility, accessibility, localization, personalization, convenience, security, responsiveness, and ease of use, as well as being able to attain cost and time reduction, access location-based and personalized recommendation services, access cloud storage services, select m-payment methods, and report on user satisfaction, etc. Strategic objectives are specified goals transformed from the value elements associated with systems, services, and constituent groups.

MG performances: MG performances are actual outputs and outcomes generated and measured from implementing, operating, and controlling MG systems and services. Collected data of specified key performance indicators (KPIs) can be analyzed to reflect levels of objective achievement and satisfaction in terms of differences between proposed and created MG values for services systems and all stakeholders. For instance, some KPIs for citizen value of the m-Tax case afore-mentioned can be level of personalization, level of time and cost saving, level of satisfaction in ease of use and usefulness, etc. And subsequently the strategic objectives for MG performances can be set to achieve $90 \%$ and $85 \%$ for level of user satisfaction regarding ease of use and usefulness respectively.

MG resources: MG resources are financial and other necessary supports for MG development and operation. Major resources include budgets, equipments, human resources, technology infrastructure, management capabilities, and domain knowledge.

MG costs: MG costs are necessary expenditures for initiating and implementing MG programs, for managing and sustaining MG operations, and for accessing and utilizing MG services. Essential costs include expenses and charges on MG systems and services development, promotion, operation, maintenance, improvement, usage, feedback processing, as well as security and privacy control. 
MG strategies and action plans: MG strategies and action plans are the specifications of strategic objectives, implementation processes, management functions and activities for building and operating MG business models, as well as for assuring value creation for all stakeholders in the MG environment.

Based on this MG business model framework, the planning and design of a suitable business model, the implementation and operation of the created business model in a proper way, as well as the evaluation and control of the performance outcomes for sustaining continuous improvement, can be carried out efficiently and effectively. The MGvBM framework incorporates concepts and methods in the fields of value chain, value management, strategic management and performance measurement. It takes into account all components of major previously presented EG and MG business models in the literature such as in $[5,9,11,20,21,33]$, and enables a broader scope as well as flexibility for developing and using business models in the public domain. The MGvBM framework is applicable to different levels of MG programs/projects and applications. Foe validation purpose, a 5-year nation wide m-/u-government program, a few central government led $\mathrm{m}$-taxation and $\mathrm{m}$-tourism services systems projects, and a couple of local government launched m-marketing and smart city projects on mobile apps are reviewed for revealing the feasibility of adopting the MGvBM framework and for proposing BM restructuring and improvement suggestions for subsequent MG development.

\section{The Development and Management of MG Business Models}

To enhance the development and management of MG business models, we adopt the build-evaluate approach from design science technology and extend it to cover the whole process. The complete development and management process for MG business models contains planning, design, implementation, operation, evaluation, and control stages. Steps to be taken in the planning stage for building MG business models include (1) identifying MG stakeholders with roles and relationships, (2) identifying MG values for proposing to all stakeholder groups, (3) identifying MG systems and services for different user groups to create, deliver, and capture MG values, (4) identifying resources needed and available for MG project management as well as service system development and operations, (5) identifying costs required for conducting necessary development works and management processes to sustain continuous operation and improvement, (6) identifying performance indicators for evaluating MG effectiveness and success, and (7) transforming value into strategic objectives and formulating associated strategies. In the design stage, work steps include (1) specifying relationships between objectives, critical success factors (CSF), and actions, (2) selecting, classifying and weighting key performance indicators (KPIs) based on the ends-CSF-means relationships, and (3) setting up action plans with management functions and processes for achieving specified performances and goals. In the implementation and operation stages, action plans are implemented and operated with output data collected for all performance indicators. In the evaluation 
and control stages, performance outcomes associated with all stakeholder groups and the entire MG project/application are measured, the gap analysis is conducted, and necessary improvement actions are specified and taken.

To facilitate the MGvBM development processes through strategic planning, to performance measurement, a number of methods and tools are used in different stages including the balanced scorecard (BSC), strategy map (SM), ends-means analysis (EMA), critical success factors (CSF), analytic hierarchy process (AHP), and strategy gap analysis (SGA), etc. Specifically for the adoption and adaptation of the BSC method, four specified BSC perspectives representing MG stakeholder groups and associated value dimensions are the public beneficiaries perspective with citizen value and business value, the government internal organization and process perspective with employee value and organization value, the government service chain perspective with entire service chain value and values for all participating parties, as well as the society and national environments perspective with society value and nation value. Figure 2 illustrates the MGvBM-BSC perspectives with some major identified BM components and elements for m-government.

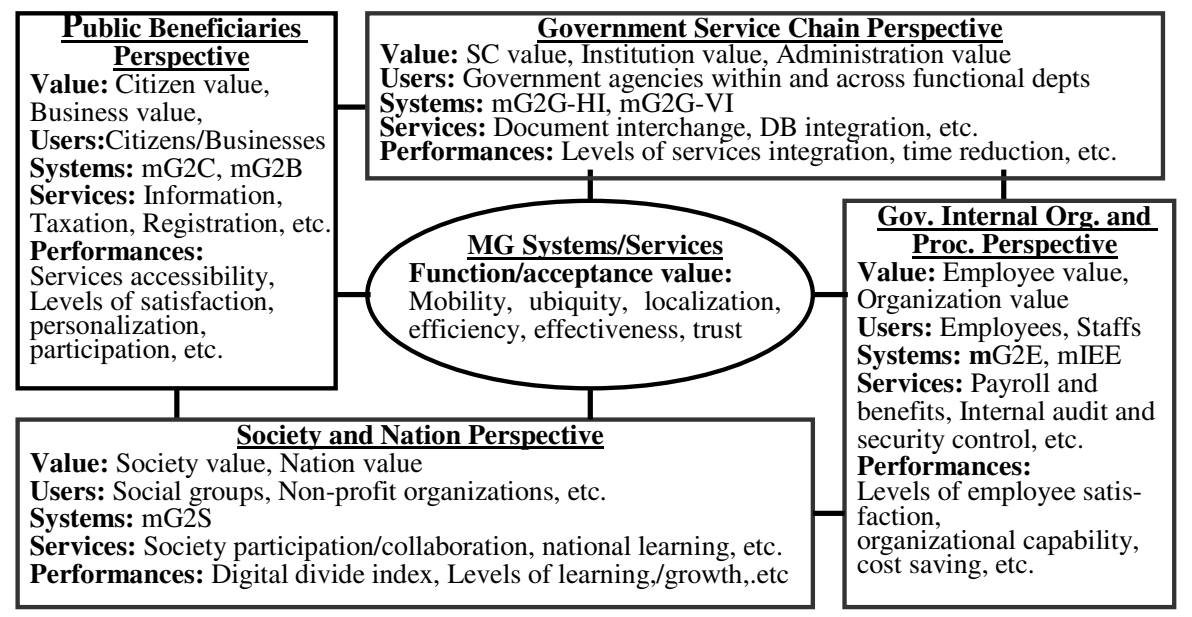

Fig. 2. The four MGvBM-BSC perspectives

Within each of the MGvBM-BSC perspectives, values, stakeholder groups, systems, services, and performance indicators related to MG projects and applications can be structurally linked and presented. For instance, in the public beneficiaries perspective, the MG user groups include citizens and businesses. The value types considered are citizen value and business value. The associated MG systems include $\mathrm{mG} 2 \mathrm{C}$ and $\mathrm{mG} 2 \mathrm{~B}$. The value-added $\mathrm{MG}$ services provided in $\mathrm{mG} 2 \mathrm{C}$ and/or $\mathrm{mG} 2 \mathrm{~B}$ systems include $\mathrm{m}$-information, $\mathrm{m}$-taxation, m-tourism, m-registration, $\mathrm{m}$-transaction, and m-payment services, etc. The MG value indicators for performance measurement include information and service accessibility, time and location convenience, cost efficiency, level of satisfaction, level of personalization, and level of participation, 
etc. For all the BM components in the BSC perspectives, more detailed specifications can be provided. For example, specific mG2C services identified for MG tourism applications may include (1) mobile information services for accessing government information about news, weather, traffic, and tourism events, (2) mobile notification and alert services for sending text message alerts about emergency conditions, and reminders about other environmental regulations, (3) mobile transaction and payment services for purchasing tickets to enter national parks or other sightseeing destinations, (4) location-based services for accessing GPS-enabled tour guides and road maps, nearby available perking lots, as well as restaurants and stores with price promotion in an acceptable distance range, (5) mobile community services for connecting friends to share information and experiences, (6) mobile reporting services for sending multimedia information to the authorities about real-time traffic conditions or accidents, and/or (6) other mobile tourism related services with personalized, collaborative, location-based, and context-aware features. Value proposition to all stakeholders is undertaken in the planning stage. In the implementation and operation stage, values can be created when systems are developed with sufficient functions and high acceptance, and services are delivered that match users' needs with high satisfaction. Whether values have been created, and/or whether the actual created values meet the pre-specified performance goals need to be assessed and analyzed in the evaluation stage. In the control stage, necessary actions for improvement are taken to ensure value capture and to sustain the continuous MG development and operations.

\section{Conclusions}

In this paper, we propose a value-centric business model framework for mobile government. Model components of the BM framework include MG stakeholders, MG values, MG systems, MG services MG resources, MG costs, MG performances, and MG strategies and action plans. MG stakeholders are classified into four constituent groups including public beneficiaries, government internal organization and process, government service chain, as well as society and national environments. Based on the proposed MGvBM framework, suitable MG business models can be built to support the planning, design, implementation, operation, and evaluation of various scales of MG projects and applications. An adaptive balanced scorecard with four stakeholder groups and value perspectives is created to facilitate the strategic planning through performance measurement processes of the MG development and management cycle. For any specific MG projects and applications, corresponding stakeholders, values, systems, services, strategic objectives, critical success factors, action plans, and key performance indicators can be structurally linked and presented with respect to each of the MGvBM-BSC perspectives. The contributions of this paper include (1) providing a value-centric business model framework that is taking a broader view, more flexible, and practically operable and measurable for guiding the development and utilization of MG business models, (2) incorporating value chain, value management, and design science concepts to take into account major issues such as 
creating values for all value chain stakeholders, managing the value proposition, creation, capture, assessment, and control cycle, as well as enabling design-buildoperate-evaluate processes, and (3) creating a potential for adopting and adapting the proposed vBM framework and development process to fit the characteristics and needs of e-government and e-participation. Future works will include validating the proposed business model framework and development process by conducting empirical testing in a variety of MG application domains.

\section{References}

1. Afuah, A., Tucci, C.L.: Internet Business Models and Strategies: Text and Cases. McGraw-Hill (2001)

2. Amit, R., Zott, C.: Value Creation in E-Business. Strategic Management Journal 22(6-7), 493-520 (2001)

3. Barber, E.: How to Measure the Value in Value Chains. International Journal of Physical Distribution \& Logistics Management 38(9), 685-698 (2008)

4. Criado, J.I., Sandoval-Almazan, R., Gil-Garcia, J.R.: Government Innovation Through Social Media. Government Information Quarterly 30(4), 319-326 (2013)

5. de Reuver, M., Bouwman, H., Haaker, T.: Mobile Business Models: Organizational and Financial Design Issues That Matter. Electronic Markets 19(1), 3-13 (2009)

6. de Reuver, M., Stein, S., Hampe, J.F.: From eParticipation to Mobile Participation: Designing a Service Platform and Business Model for Mobile Participation. Information Polity $18(1), 57-73$ (2013)

7. Fong, P.S., Shen, Q., Cheng, E.W.L.: A Framework for Benchmarking the Value Management Process. Benchmarking: An International Journal 8(4), 306-316 (2001)

8. Hossain, M.D., Moon, J., Kim, J.K., Choe, Y.C.: Impacts of Organizational Assimilation of e-Government Systems on Business Value Creation: A Structuration Theory Approach. Electronic Commerce Research and Applications 10(5), 576-594 (2011)

9. ITU. Understanding m-Government Adoption: M-Government Mobile Technologies for Responsive Governments and Connected Societies. OECD Publishing (2011)

10. IVM. Value Management Techniques. Online document of The Institute of Value Management, http: / / ivm.org.uk/techniques (retrieved by April 2014)

11. Janssen, M., Kuk, G.: E-government Business Models for Public Service Networks. International Journal of Electronic Government Research 3(3), 54-71 (2007)

12. Keen, P., Williams, R.: Value Architectures for Digital Business: Beyond the Business Model. MIS Quarterly 37(2), 643-647 (2013)

13. Lariviere, B., et al.: Value Fusion: The Blending of Consumer and Firm Value in Distinct Context of Mobile Technologies and Social Media. Journal of Service Management 24(3), 268-293 (2013)

14. Lee, S.M., Tan, X., Trimi, S.: Current Practices of Leading e-Government Countries. Communications of the ACM 48(10), 99-104 (2005)

15. Leem, C.S., Jeon, N.J., Choi, J.H., Shin, H.G.: A Business Model (BM) Development Methodology in Ubiquitous Computing Environments. In: Gervasi, O., Gavrilova, M.L., Kumar, V., Laganá, A., Lee, H.P., Mun, Y., Taniar, D., Tan, C.J.K. (eds.) ICCSA 2005. LNCS, vol. 3483, pp. 86-95. Springer, Heidelberg (2005)

16. Luna-Reyes, L.F., Gil-Garcia, J.R., Romero, G.: Towards a Multidimensional Model for Evaluating Electronic Government: Proposing a More Comprehensive and Integrative Perspective. Government Information Quarterly 29(3), 324-334 (2012) 
17. Nah, F.F.H., Siau, K., Sheng, H.: The Value of Mobile Applications: A Utility Company Study. Communications of the ACM 48(2), 85-90 (2005)

18. Ntalinai, M., Costopoulou, C., Karetsos, S.: Mobile Government: A Challenge for Agriculture. Government Information Quarterly 25(4), 699-716 (2008)

19. Osterwalder, A., Pigneur, Y.: Business Model Generation: A Handbook for Visionaries, Game Changers, and Challengers, 1/E. John Wiley \& Sons (2010)

20. Panagiotopoulos, P., Al-Debei, M.M., Fitzgerald, G., Elliman, T.: A Business Model Perspective for ICTs in Public Engagement. Government Information Quarterly 29(2), 191202 (2012)

21. Peinel, G., Jarke, M., Rose, T.: Business Models for eGovernment Services. Electronic Government: An International Journal 7(4), 380-401 (2010)

22. Schmidt-Rauch, S., Schwabe, G.: Designing for Mobile Value Co-creation - The Case of Travel Counselling. Electronic Markets 24(1), 5-17 (2014)

23. Schubert, P., Hampe, J.F.: Mobile Communities: How Viable are Their Business Models? An Exemplary Investigation of the Leisure Industry. Electronic Commerce Research 6(1), 103-121 (2006)

24. Teece, D.J.: Business Models, Business Strategies and Innovation. Long Range Planning (2009) (in press)

25. Timmers, P.: Business Models for Electronic Markets. Electronic Markets 8(2), 3-8 (1998)

26. Traunmüller, R.: Mobile government. In: Andersen, K.N., Francesconi, E., Grönlund, A., van Engers, T.M. (eds.) EGOVIS 2011. LNCS, vol. 6866, pp. 277-283. Springer, Heidelberg (2011)

27. Trimi, S., Sheng, H.: Emerging Trends in M-government. Communications of the ACM 51(5), 53-58 (2008)

28. Varshney, U.: Business Models for Mobile Commerce Services: Requirements, Design, and the Future. IT Professional 10(6), 48-55 (2008)

29. Weinhardt, C., Anadasivam, A., Blau, B., StoBer, J.: Business Models in the Service World. IT Professional 11(2), 28-33 (2009)

30. Wu, H., Ozok, A.A., Gurses, A.P., Wei, J.: User Aspects of Electronic and Mobile Government: Results From a Review of Current Research. Electronic Government: An International Journal 6(3), 233-251 (2009)

31. Yu, C.C.: Linking the Balanced Scorecard to Business Models for Value-Based Strategic Management in e-Business. In: Bauknecht, K., Pröll, B., Werthner, H. (eds.) EC-Web 2005. LNCS, vol. 3590, pp. 158-167. Springer, Heidelberg (2005)

32. Yu, C.C.: Building a Value-Centric e-Government Service Framework Based on a Business Model Perspective. In: Wimmer, M.A., Scholl, H.J., Ferro, E. (eds.) EGOV 2008. LNCS, vol. 5184, pp. 160-171. Springer, Heidelberg (2008)

33. Yu, C.C.: Value Proposition in Mobile Government. In: Wimmer, M.A., Janssen, M., Scholl, H.J. (eds.) EGOV 2013. LNCS, vol. 8074, pp. 175-187. Springer, Heidelberg (2013)

34. Zott, C., Amit, R.: The Fit Between Product Market Strategy and Business Model: Implications for Firm Performance. Strategic Management Journal 29(1), 1-26 (2008) 